\title{
Evaluation of in-vitro Anti-Inflammatory Activity of Gallic Acid
}

\section{Raksha Agrawal' ${ }^{1}$, Aditya Ganeshpurkar'1, Megha Verma², Pradeep Golani², Devendra Singh Lodhi' ${ }^{2}$, Namarta Jain ${ }^{2}$}

${ }^{1}$ Shri Ram Institute of Technology Pharmacy, Jabalpur, M.P-482003 India

${ }^{2}$ Gyan Ganga Institute of Technology \& Sciences, Bargi Hills, Jabalpur M.P-482003 India

Corresponding Author: Raksha Agrawal

\begin{abstract}
Gallic acid's anti-inflammatory effect was studied at various concentrations, including $50,100,150,200$, and $250 \mathrm{ug} / \mathrm{ml}$. Gallic acid's anti-inflammatory effect was assessed using two in-vitro assays: proteinase inhibition and albumin denaturation. The greatest proteinase inhibition activity of 52.83 percent was achieved at a concentration of $250 \mathrm{ug} / \mathrm{ml}$, according to the results. It also revealed that at $250 \mathrm{ug} / \mathrm{ml}$, the maximum percentage inhibition in albumin denaturation was 74.79 percent. Gallic acid's antiproteinase and albumin denaturation activities both increase with increasing concentrations, according to this research.
\end{abstract}

Key Words: Gallic acid, Anti-Inflammatory, InVitro Assays, Albumin Denaturation, Proteinase activity

\section{INTRODUCTION}

Proteins are an essential ingredient for human health. They serve as both a building block for bodily tissues and a source of fuel. Proteins are polymeric chains that are made up of amino acids linked by peptide bonds. It is a necessary nutrient for the human body's growth and upkeep. It is an important structural component of all of the body's cells. They serve as building blocks for nucleic acids, coenzymes, hormones, immunological response, cellular repair, and other life-sustaining compounds. They are essential for the structure, function, and control of the body's tissues and organs, and they do the majority of their activity in cells. Hormones provide signals to coordinate biological activities between different cells, tissues, and organs, while antibodies aid to protect the body from numerous diseases. Protein denaturations are the result of a slight disturbance of a protein's structure, which causes changes in its biological, chemical, and physical properties. During denaturation, proteins' secondary and tertiary structures are disturbed and possibly destroyed. The primary structure (amino acid sequence) remains unaltered after the treatment since denaturation reactions aren't strong enough to break peptide bonds. The normal alphahelix and beta sheets of a protein unravel during denaturation, resulting in a random shape. When the secondary structure (hydrogen bonds to amides) and tertiary structure bonding connections are disrupted, denaturation occurs. Four types of bonding contacts between "side chains" in tertiary structure can be broken: hydrogen bonding, salt bridges, disulfide bonds, and non-polar hydrophobic interactions. As a result, a wide range of chemicals and situations can produce denaturation. The most common symptom of the protein denaturation process is precipitation or coagulation. Denaturation can also be caused by changes in $\mathrm{pH}$, which modify the chemistry of amino acids and their residues. When the $\mathrm{pH}$ of amino acids changes, the ionisable groups can become ionised. Unfolding can be induced by a change in $\mathrm{pH}$ to more acidic or basic 
circumstances. The $\mathrm{pH}$ range for acidinduced unfolding is typically 2 to 5 , while the $\mathrm{pH}$ range for base-induced unfolding is usually 10 or higher. Protein denaturation is also an outcome of cell death. Proteins which are denatured can have a variety of properties from structural alterations and solubility loss to aggregation caused by hydrophobic group exposure. Proteins which are denatured are unable to function because they have lost their 3-dimensional structure. Herbal plants have long been used to cure a variety of ailments and disorders, as we all know. Herbal plants include a variety of components that have different therapeutic effects. Herbal medications have been widely utilised for centuries due to the low number of side effects they cause. Herbal medications have also grown in popularity in recent years as a result of their easy availability and low number of negative effects. Polyphenols are micronutrients found in certain plant-based meals. Polyphenols can aid with digestion problems, weight management problems, diabetes, neurodegenerative illness, and cardiovascular disease. Polyphenols, on the other hand, may have a number of unfavourable side effects. When taking polyphenol supplements instead of receiving them naturally through food, this is the most typical side effect. The possibility for polyphenols is the most common adverse effect with the most scientific proof. [6] Gallic acid (also called 3,4,5trihydroxybenzoic acid) is a phenolic acid found in plants like oak bark, gallnuts, elderberry, tea leaves, witch hazel and others. $\mathrm{C}_{6} \mathrm{H}_{2}(\mathrm{OH})_{3} \mathrm{COOH}$ is the chemical formula for gallic acid. Both as a free substance and as a component of hydrolysable tannins, it can be detected. Dimers of gallic acid, such as ellagic acid, are usually formed when the gallic acid groups are bound together. Gallic acid and glucose, or ellagic acid and glucose, are produced during the hydrolysis of hydrolysable tannins, and are known as gallotannins and ellagitannins, respectively. Digallic and trigallic acids are intermolecular esters (depsides), are formed by gallic acid (depsidones). Gallic acid is extensively used as a standard in the Pharma industries The Folin-Ciocalteau assay is used in industry to determine the phenol concentration of various analytes; results are given in gallic acid equivalents. Gallic acid can potentially be used as a starting material for the hallucinogenic alkaloid mescaline. Gallic acid inhibits HAT, p300, and CBP acetyltransferases in vitro, as well as p300mediated RelA acetylation and ant apoptotic and cell survival genes controlled by NF-Kb . It also inhibits PMN function, lowers MPO, and slows the rate of cytochrome c synthesis. The ethyl ester of gallic acid reduces acid-induced abdominal constriction and hyperalgesia. Inflammatory arthritis is reduced by bergenin, a glycoside of gallic acid. [8] Arthritis is a common degenerative disease that affects the joints that causes swelling, pain and stiffness. Warmth, swelling, and redness might be seen around the joints. In the affected area, there is a wide range of pain and difficulties moving joints .Rheumatoid arthritis is an autoimmune illness that causes damage to the joints. The formation of reactive oxygen species is linked to joint damage (ROS). [9] TNF- and interleukins are two biological substances that play a key function in the progression of inflammation to the cells. The treatment focuses on the use of antiinflammatory drugs, which have helped to reduce joint pain. DMARDS (disease modifying rheumatoid arthritis drugs) can aid with joint inflammation. Immunosuppression occurs as these medications are used more frequently, increasing the risk of infection from other sources. [10] Hypertension, dyspepsia, heart failure, and renal dysfunction are some of the other side effects of analgesics-antiinflammatory medicines. Proteinase inhibitors give a substantial amount of protection during inflammatory reactions by inhibiting leukocyte proteinase [11].

The objective of the present work is to determine the action of pyrogallol over 
inhibition of protein denaturation and antiproteinase activity.

\section{MATERIALS AND METHOD 2.1. MATERIALS}

Fresh extract of pyrogallol was obtained from the college laboratory of Shri Ram Institute of Technology, Pharmacy.

\subsection{REAGENTS}

Trypsin, Tris-HCl buffer, casein, perchloric acid and egg albumin.

\subsection{ANTIPROTEINASE ACTION}

Proteins have a critical function in arthritis prevention strategies. As a result proteinase reversible action (which is responsible for the degradation of a protein's 3D shape) reduces clinical arthritis. Oyedepo et al [11] performed and modified this procedure. The test samples were incubated with $0.06 \mathrm{mg}$ Trypsin, $1 \mathrm{ml}$ of $20 \mathrm{Mm}$ tris HCL buffer (pH-7.4) at $37^{\circ} \mathrm{C}$ for 5 minutes, and then $1 \mathrm{ml}$ of 0.8 percent w/v casein was added, and the combination was incubated for another 20 minutes. To arrest the reaction, $2 \mathrm{~mL}$ of $70 \%$ perchloric acid was added. The mixture was centrifuged, and absorbance was measured against a blank at $210 \mathrm{~nm}$ (containing only buffer). The standard drug piroxicam is treated in the same way. The experiment was carried out three times. The formula used to calculate the percentage inhibition of proteinase inhibitory activity.
Percent inhibition

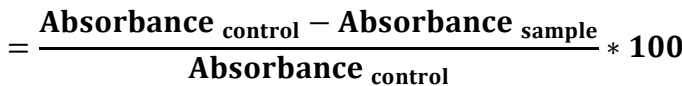

\subsection{ACTIVITY OF ALBUMIN DENATURATION}

The denaturation of albumin was measured using the standard technique [10] and Sakat et al [12]. The reaction mixture consisted of the test sample and a 1\% aqueous egg albumin solution. The samples were heated at $57^{\circ} \mathrm{C}$ for 30 minutes after being incubated at $37^{\circ} \mathrm{C}$ for 20 minutes. The turbidity was measured spectrophotometrically at $660 \mathrm{~nm}$ after the samples were cooled. This was then compared with the standard drug piroxicam. The experiment was carried out three times. The formula used to calculate the percentage of protein denaturation inhibition.

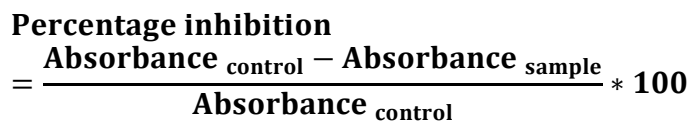

\subsection{STATISTICAL ANALYSIS}

For both in vitro assays tested, all data is presented as the mean minus standard deviation, and each analysis was performed in triplicate.

The average standard deviation of three observations is displayed. At *P $<0.05$, the significance was followed by the student.

\section{RESULT}

\subsection{ANTIPROTEINASE ACTIVITY}

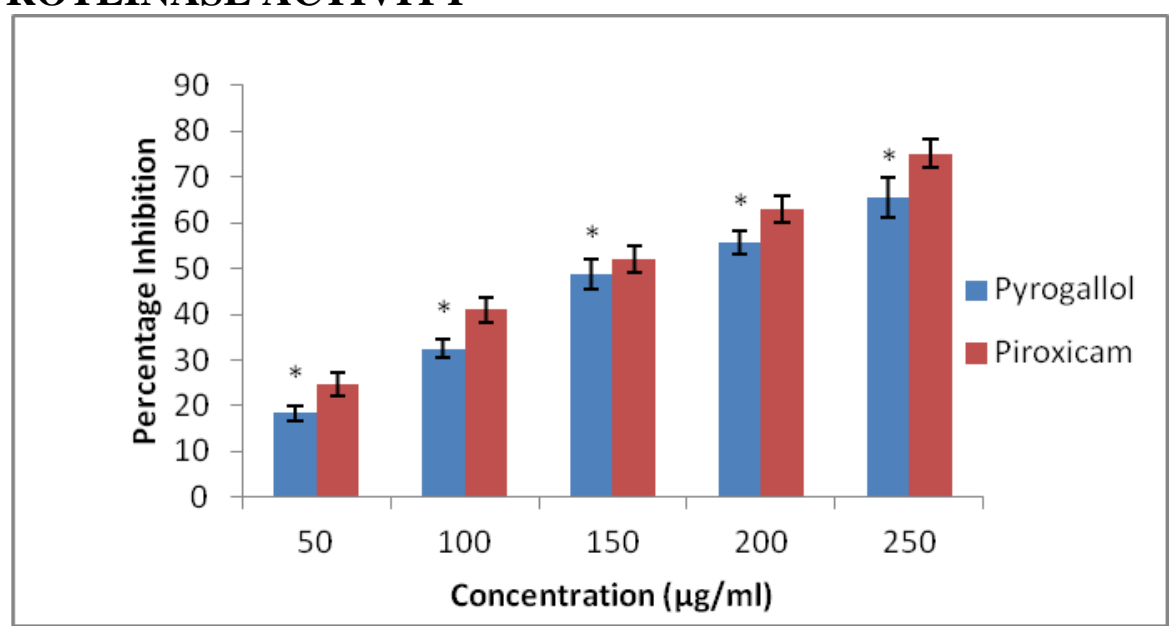

Figure 1: Effect of pyrogallol on antiproteinase The results are shown as the mean standard deviation of three observations. ${ }^{*} \mathbf{P}<$ 0.05 signifies significance. 
Proteinase inhibitors provide a considerable amount of protection against tissue damage during inflammatory reactions because leukocyte proteinase plays a crucial part in the development of tissue damage. Figure 1 shows that Pyrogallol has a considerable $(\mathrm{P}<0.001)$ antiproteinestrase activity at various concentrations. At 250 $\mathrm{g} / \mathrm{ml}$, it inhibited 52.83 percent of the bacteria. In comparison to the control, piroxicam inhibits 75.14 percent at $250 \mathrm{~g} / \mathrm{ml}$ (figure 1).

\subsection{DENATURATION OF ALBUMIN}

The capacity of pyrogallol to suppress protein denaturation has been investigated. Pyrogallol was efficient in preventing albumin denaturation caused by heat, as illustrated in Figure 2. Albumin denaturation is inhibited to a maximum of 74.79 percent $(\mathrm{P}<0.05)$. at a concentration of $250 \mathrm{~g} / \mathrm{ml}$. In comparison to control, piroxicam showed a maximal inhibition of 76.75 percent at $250 \mathrm{~g} / \mathrm{ml}$.

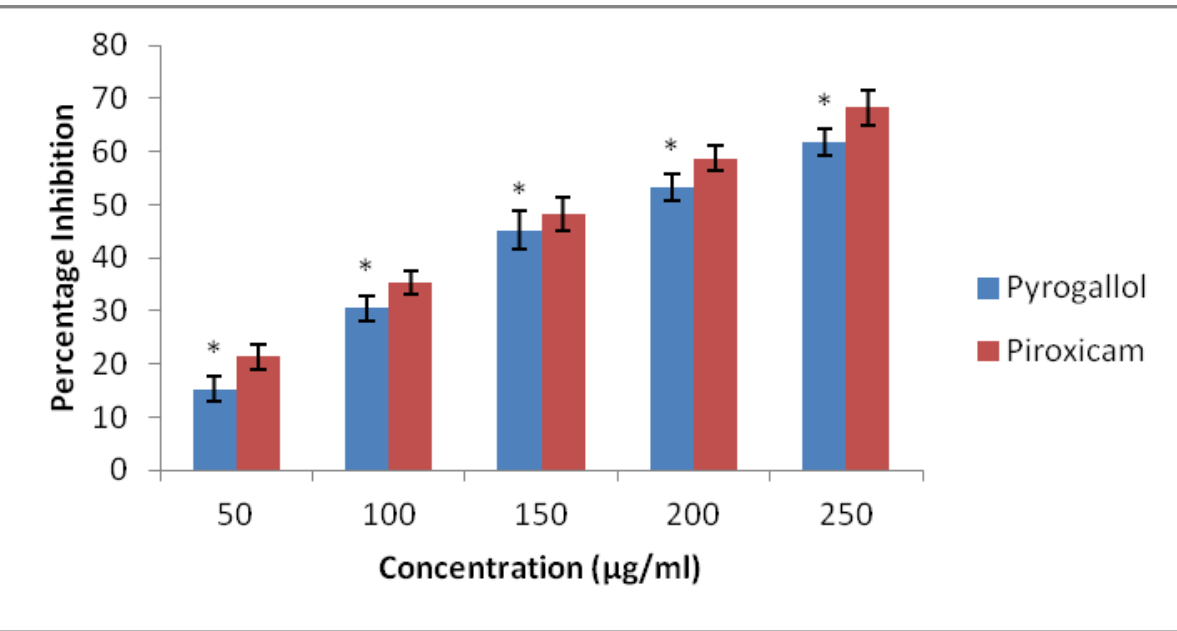

Figure 2: Effect of pyrogallol on protein denaturation activity. The results are shown as the mean standard deviation of three observations. $* \mathbf{P}<0.05$ signifies significance.

\section{DISCUSSION}

Pyrogallol's antioxidant activity may help to slow the progression of arthritis. The prognosis of arthritis factor is determined by denatured proteins. Pyrogallol was found to have inhibitory activity against albumin denaturation in this investigation, implying that it may have a protective impact against arthritis. Proteinase plays a vital role in the genesis of inflammation and, later, arthritis. Pyrogallol's antiproteinestrase activity limits the action of antiproteinase, resulting in inflammation suppression. As a result, pyrogallol is an excellent option for testing its influence on experimentally produced arthritis.

\section{SUMMARY}

Pyrogallol's anti-inflammatory effects, such as antiproteinase activity and albumin denaturation activity, were assessed in vitro. Piroxicam, a good anti- inflammatory drug, was used as a standard solution. With the use of a UV visible spectrophotometer, several dilutions of gallic acid and piroxicam were created and assessed. Percentage inhibition was calculated, and concentration vs. percentage inhibition plots were drawn.

\section{CONCLUSION}

The antiproteinase activity was found to be exactly proportional to the sample concentration, meaning that as the sample concentration increases, so does the antiproteinase activity. Maximum inhibition of $52.83 \%$ was shown at $250 \mathrm{ug} / \mathrm{ml}$. The greatest protein inhibition activity of 74.79 percent was obtained at $250 \mathrm{ug} / \mathrm{ml}$, which is a good characteristic for an antiinflammatory drug, according to the albumin denaturation investigation. Pyrogallol was discovered to be a good and powerful anti-inflammatory drug with low 
adverse effects after analysing both in vitro and in vivo actions
Abbreviations
1. $\mu g$-microgram
2. $\mathrm{ml}$ - millilitre
3. Mm- millimolar
4. w/v- weight by volume
5. nm - nanometre
6. g - gram
7. UV - ultraviolet
8. \% - percent

\section{Acknowledgement: None}

\section{Conflict of Interest: None}

\section{Source of Funding: None}

\section{Ethical Approval: Approved}

\section{REFERENCES}

1. Omotayo AR, El-Ishaq A, Tijjani LM, Segun DI. Comparative analysis of protein content in selected meat samples (cow, rabbit, and c1. Omotayo AR, El-Ishaq A, Tijjani LM, Segun DI. Comparative analysis of protein content in selected meat samples (cow, rabomparative analysis of protein content in select. Am J Food Sci Heal 2016;2(6):151-5.

2. Genton L, Melzer K, Pichard C. Energy and macronutrient requirements for physical fitness in exercising subjects. Clin Nutr 2010;29(4):413-23.

3. Lupton JR, Brooks JA, Butte NF, Caballero B, Flatt JP, Fried SK. Dietary reference intakes for energy, carbohydrate, fiber, fat, fatty acids, cholesterol, protein, and amino acids. Natl Acad Press Washington, DC, USA 2002;5:589-768.

4. Samson AL, Ho B, Au AE, Schoenwaelder SM, Smyth MJ, Bottomley SP, et al. Physicochemical properties that control protein aggregation also determine whether a protein is retained or released from necrotic cells. Open Biol 2016;6(11):160098.

5. Dyson HJ, Wright PE. Intrinsically unstructured proteins and their functions. Nat Rev Mol cell Biol 2005;6(3):197-208.

6. Manach C, Scalbert A, Morand C, Rémésy C, Jiménez L. Polyphenols: food sources and bioavailability. Am J Clin Nutr 2004;79(5):727-47.

7. Pengelly A. The constituents of medicinal plants. 2004;

8. Choi K-C, Lee Y-H, Jung MG, Kwon SH, Kim M-J, Jun WJ, et al. Gallic acid suppresses lipopolysaccharide-induced nuclear factor- $\mathrm{\kappa B}$ signaling by preventing RelA acetylation in A549 lung cancer cells. Mol Cancer Res 2009;7(12):2011-21.

9. Gupta BM, KK MA, Gupta R. Arthritis Research in India: A Scientometric Assessment of Publications Output during 2007-16. SciFed J Orthop Rheumatol 2017;1(1).

10. MIZUSHIMA $\mathrm{Y}$, KOBAYASHI $\mathrm{M}$. Interaction of anti???inflammatory drugs with serum proteins, especially with some biologically active proteins. J Pharm Pharmacol 1968;20(3):169-73.

11. Oyedapo 0.0., Famurewa AJ. Antiprotease And Membrane Stabilizing Activities Of Extracts Of Fagara Zanthoxylozdes, Olax Subscorpzozdes And Tetrapleura Tetraptera. Int J Pharmacogn 1995;33(1):65-9.

12. Kinne RW, Stuhlmüller B, Burmester GR. Cells of the synovium in rheumatoid arthritis. Macrophages. Arthritis Res. Ther.2007;9(6).

How to cite this article: Agrawal R, Ganeshpurkar A, Verma M et.al. Evaluation of in-vitro anti-inflammatory activity of gallic acid. International Journal of Research and Review. 2021; 8(12): 323-327. DOI: https://doi.org/10. 52403/ijrr.20211240 